\title{
A supraventricular tachycardia showing alternation of the QRS interval
}

\author{
R. J. van Bommel • E. G. Weijers • H. J. Wellens
}

Published online: 4 August 2013

(C) The Author(s) 2013. This article is published with open access at Springerlink.com

A 21-year-old woman presented to the emergency department with sustained palpitations for approximately $1 \mathrm{~h}$. She had had these palpitations previously, but they always stopped spontaneously. On presentation, she had no chest pain and no dyspnoea. She had not consumed any alcohol, coffee or other substances. Her ECG showed a narrow QRS complex tachycardia with a frequency around $170 \mathrm{bpm}$ (Fig. 1a). Following adenosine administration, the tachycardia terminated with the ECG showing a sinus rhythm of $70 \mathrm{bpm}$ (Fig. 1b). What is your differential diagnosis and can you explain the mechanism?
Fig. 1 a Narrow complex tachycardia of approximately $170 \mathrm{bpm}$ upon presentation; $\mathbf{b}$ ECG after administration of adenosine showing sinus rhythm of $70 \mathrm{bpm}$

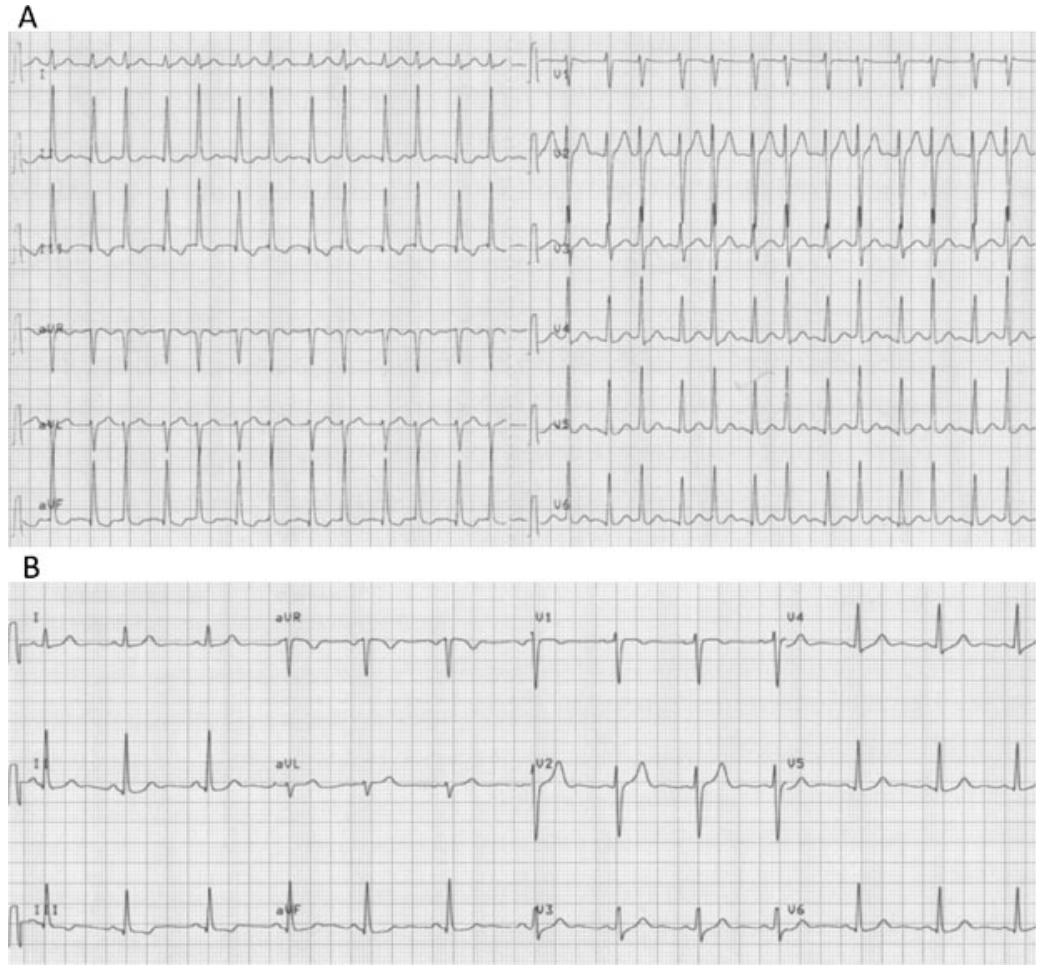

R. J. van Bommel $(\bowtie) \cdot$ E. G. Weijers

Department of Cardiology, Groene Hart Ziekenhuis,

Bleulandweg 10, 2803, HH Gouda, the Netherlands

e-mail: r.j.van_bommel@lumc.nl

\section{H. J. Wellens}

Cardiovascular Research Institute, Henric van Veldekeplein 21,

6211, TG Maastricht, the Netherlands
Answer

You will find the answer elsewhere in this issue.

Open Access This article is distributed under the terms of the Creative Commons Attribution License which permits any use, distribution, and reproduction in any medium, provided the original author(s) and the source are credited. 